\title{
Sobre a singularidade das formas correferenciais metafóricas
}

\section{Erik Miletta Martins ${ }^{1}$}

Resumo: Este artigo tem por objetivo discutir as bases epistemológicas, teóricas e metodológicas para a definição e análise de estratégias textuais correferenciais recategorizadoras - sob a forma de anáforas nominais como as sinonímias e as paráfrases - nas quais há emprego de metáforas. Aponta-se, aqui, a singularidade destes processos diante de dois movimentos inferenciais distintos, relativos à correferência e à configuração conceptual da metáfora no efeito de recategorização. Para atingirmos este objetivo, trazemos alguns exemplos extraídos de um ambiente retórico religioso, altamente produtivo para a ilustração da peculiaridade teóricometodológica dos processos co-referenciais metafóricos.

Palavras-chave: Processos referenciais. Correferência.Metáfora. Recategorização.

\begin{abstract}
The goal of this article is to discuss the epistemological, theoretical and methodological basis for the definition and analysis of co-referential textual strategies - manifested as nominal anaphors such as synonyms and paraphrases on which there is use of metaphors. We point out the singularity of these processes in face of two distinct inferential movements, related to co-reference and the conceptual configuration of metaphor. To do so, we explore some examples from a religious rhetorical environment, highly productive to illustrate the theoreticalmethodological peculiarity of metaphorical co-referential processes.
\end{abstract}

Keywords: Referential processes. Co-reference. Metaphor. Recategorization.

Resumen: El objetivo de este artículo es discutir la base epistemológica, teórica y metodológica para la definición y análisis de estrategias textuales correferenciales manifiestas como anáforas nominales tales como sinonimias y paráfrasis - en que hay el empleo de metáforas. Se destaca la singularidad de estos procesos ante dos movimientos inferenciales distintos, relativos a la correferencia y a la configuración conceptual de la metáfora en el efecto de la recategorización. Para alcanzar este objetivo, traemos algunos ejemplos extraídos de un ambiente retórico religioso, altamente productivo para la ilustración de la peculiaridad teórico-metodológica de los procesos correferenciales metafóricos.

\footnotetext{
${ }_{1}$ Professor Adjunto (Linguística) da Universidade Federal do Rio Grande do Norte (UFRN) Possui graduação (2008), mestrado (2011) e doutorado (2015) em Linguística pela Universidade Estadual de Campinas (2008).
}

Este artigo está licenciado sob forma de uma licença Creative Commons Atribuição 4.0 Internacional

que permite uso irrestrito, distribuição e reprodução em qualquer meio, desde que a publicação

original seja corretamente citada. https://creativecommons.org/licenses/by/4.0/deed.pt BR. 
Palabras clave: Procesos referenciales. Correferencia. Metáfora. Recategorización.

\section{Introdução: o problema da referência na agenda dos estudos sociocognitivos do texto}

No Brasil, os problemas levantados portrabalhos dedicados ao tema da referenciação norteiam questões teóricas, metodológicas e epistemológicas centrais à agenda de investigação dos estudos sobre texto e discurso (BENTES E ALVES FILHO, 2012). Não por acaso, a questão da construção da referência vem sendo responsável por delimitar um campo de estudos no qual a linguagem é percebida - e analisada - em meio a relações intersubjetivas e sociais (MONDADA; DUBOIS, 2003 [1995]), delimitadaspor práticas simbólicas de “negociação da realidade" (GOFFMAN, 1974), e protagonizadas por processos vários de "textualização ou discursivização da realidade" (KOCH, 2002).

No campo acima delimitado, noções caras aos estudos do texto, como coesão, coerência ${ }^{2}$ - e demais critérios de textualidade 3 - gênero ${ }^{4}$, tópico 5 , contexto, etc. e aos estudos da cognição na linguagem, como categorização, inferenciação, metáfora conceptual, etc. impactam em e são impactadas por avanços e acordos comunssobre o problema semântico-textual da referência, elementar à questão da significação

\footnotetext{
2 "A coerência vai passar a ser vista como uma construção situada dos interlocutores" (Koch, 2004, p. 47).

3 Remeto aqui à leitura de Koch $(2002,2004)$ sobre os critérios de textualidade desenvolvidos por Beaugrande e Dressler (1981 apudKOCH, 2004): coesão, coerência (características "centradas no texto"), situacionalidade, informatividade, intertextualidade, intencionalidade e aceitabilidade ("centradas no usuário").

4 Ver Cavalcante et al. (2007).

5 Ver Marcuschi (2006), Koch (2008).
} 
linguística. A centralidade da noção de referência também organiza um quadro no qual a articulação entre tais noções contribui para a formação de uma "perspectiva sociocognitiva" (SALOMÃO, 1999, 2005, 2009; KOCH; CUNHA-LIMA, 2004, MARCUSCHI,2003, 2005).

Nesta perspectiva, lembra-nos Marcuschi, "a própria referência é determinada no contexto da cena comunicativa ou nas molduras comunicativas" (2005, p. 93); não por acaso, reivindica-se à significação a dimensão do "trabalho ecológico do sujeito cognitivo", isto é, um trabalho orientado numa moldura específica (física, mental e social) e capaz de "movimentar contínuas semioses para a construção do sentido como entendimento localmente validado" (SALOMÃO, 2005, p. 153).

Posto que a pergunta sobre a referência resvala no clássico problema de como damos a conhecer o mundo através da linguagem o que implica, dentre outras coisas, problemas epistemológicos comuns aos estudos sobre a cognição e aos estudos sobre a linguagem - a própria noção de texto revela-se impactada.Nota-se este impacto quando é definida, por exemplo, enquanto "forma de cognição social que permite ao homem organizar cognitivamente o mundo" $(\mathrm{KOCH}$, 2002,p. 157). Por isso, é cada vez mais comum aos autores e autoras da Linguística Textual evocar noções afeitas à língua e à cognição dentro de uma dinâmica processual e de mútua constitutividade; é o caso do par "objeto de discurso" e "categorização", propostos enquanto processos distintos, mas indissociáveis e essenciais à construção e estabilização da referência (MONDADA; DUBOIS (2003; [1995]).

Diante do problema central da referência, os objetos e indagações gerais próprias aos estudos sociocognitivos do texto, plantados em 
nossas terras pelo homenageado neste número e por Ingedore Koch, ficam marcados poruma inescapável“solidariedade entre processos linguísticos e cognitivos na construção (e não apenas no processamento) textual" (MORATO, no prelo) do sentido. Admitir este tipo de relação solidária nos permite, por exemplo, entender com mais clareza a relação entre implicitação e explicitação de sentidos textuais, pois a construção da referência é lugar altamente privilegiado para enxergarmos"relações estreitas e solidárias entre processos de explicitação e implicitação do sentido textual” (MORATO et al., 2012).

Deve-se apontar, contudo, que esta perspectiva não é homogênea, incluindo uma série de inclinações e interesses distintos. Embora o problema da referência seja responsável por um diálogo cada vez mais profícuo entre a Linguística Cognitiva e a Linguística Textual ${ }^{6}$, destacamos aqui investigações voltadas sobretudo à compreensão das dimensões locais, sociocognitivamente situadas, de atividades formulativas-interacionais; é a perspectiva Textual-Interativa (JUBRAN, 2006). Detalhar o trabalho de (co-)construção referencial, emergente em meioavariadas estratégias empregadasna condução de intenções comunicativas, contribui para revelaro percurso inferencial no qual atuam processos responsáveis pela resolução de relações dêiticas e anafóricas. Nesta perspectiva, estaatividade élargamenteconduzida por processos implícitos de significação, influenciados tanto por regras pragmáticas admitidas e/ou negociadas em uma interação (oral ou

\footnotetext{
${ }^{6}$ Apontamos aqui que este diálogo pode ser melhor realizado se admitirmos que a Linguística Textual pode ajudar a colocar em cheque a rigidez hierárquica entre língua e cognição operacionalizada pela Linguística Cognitiva, em especial quando reduz complexas dinâmicas sociais a instanciações de processos cognitivos individuais (MARTINS, 2015), primários e universais (LEEZENBERG, 2015 [2013]).
} 
escrita), quanto pela atuação de esquemas cognitivos estruturados, como scripts, frames (em suas variadas acepções: GOFFMAN, 1974, MINSKY 1975, FILLMORE, 1982, TANNEN 1993, MORATO et al.,2017), metáforas conceptuais, entre outros. A propósito dessa dinâmica,do ponto de vista do fluxo textual, Morato et al. (2017, p. 94) lembram-nos que:

\begin{abstract}
A forma como os indivíduos recategorizam, predicam e ancoram textualmente os referentes pode indicar algo sobre os conhecimentos organizados de suas experiências sociais: estes tanto evocam e "atualizam" frames (MORATO, 2010b; MORATO ; BENTES, 2013), quanto podem indicar conexão entre eles (VEREZA, 2013).
\end{abstract}

Também no campo dos estudos sociocognitivos do texto são efetuados diálogos interdisciplinares de variadas ordens, compromissados com o objetivo maior de entender o papel das práticas sociais na constituição da cognição humana. Compromissados com esta ideia, autores e autoras representativas de diferentes áreas, com inclinações epistemológicas e interesses variados, como Michael Tomasello, Teunvan Dijk, George Lakoff, Lorenza Mondada, Charles Fillmore, e, entre nós, Margarida Salomão, Ingedore Koch e Luiz Antônio Marcuschi, dentre outros, são constantemente evocados para a defesa de um ponto de vista em que o problema da representação referencialse apresenta completamente indissociável das práticas humanas. A reivindicação aberta de uma ontologia referencial fundamentada na práxis (MARCUSCHI, 2007), compromissada com uma epistemologia experiencialista (MARTINS, 2002)na qual as categorias do conhecimento humano organizam-se em torno de 
protótipos (ROSCH, 1978) relacionados em gradiência e contextualmente organizados,conflui para a percepção de que a língua está em "essencial continuidade" com os demais sistemas cognitivos, como a atenção, a memória e a percepção; alega-se, pois, uma “interrelação funcional” entre língua e cognição (MORATO, KOCH, 2006).

Um dos efeitos mais significativos desta tomada de posição implica a derrubada de barreiras responsáveis por forjar dicotomias já clássicas para nós da Linguística, como a existência de um tipo de conhecimento semântico oposto a um conhecimento pragmático ou enciclopédico. Superar dualismos, sejam ontológicos ou epistemológicos, é tarefa centraldesta agenda de estudo e não significa abraçar um relativismo, mas, sim, reconhecer uma "dimensão material da vida simbólica" (SALOMÃO, 2005) na qual a cognição é tratada como "rede social" que licencia/organiza/oferece estratégias sociocognitivas adotadas pelos sujeitos para atingir objetivos comunicativos e interacionais variados.

\section{Da dimensão inferencial da correferência nominal: retomada, aspectualização e avaliação do referente}

A significação referencial, assim compreendida, pode manifestarse por diferentes estratégias responsáveis pela composição do objeto de discurso (MONDADA; DUBOIS, 2003; [1995]). No caso, junto a Marcuschi e Koch (2002) podemos notar duas macroestratégias textualinterativas: refocalização e/ou alteração referencial. Para os interesses 
estabelecidos neste artigo, focamo-nos na primeira, mais especificamente quando manifestada sob a forma de Anáforas Nominais não cossignificativas, como as sinonímias, as paráfrases. Após uma breve exposição das caraterísticas mais prototípicas dessas formas, apontaremos que, quando preenchidas por metáforas, estas formas adquirem singularidade e requerem especificidade teórico-analítica nos estudos do texto.

Entre os elementos que compõem a unidade da perspectiva (SALOMÃO, 2009) sociocognitiva, chamamos a atenção para a noção de significação enquanto o processo resultante de uma projeção entre domínios cognitivos. Em relação às anáforas nominais, estamos diante de estratégias textuais de reformulaçãoresponsáveis por garantir a progressão referencial através de um movimento de retomada, explícita ou implícita, do antecedente textual, geralmente implicando aspectualização e avaliação do referente. Tomemos o seguinte exemplo ad hoc:

- Saussure é considerado o pai da Linguística Moderna. O mestre genebrino é responsável pela sistematização dessa ciência.

O caráter correferencial e recategorizador desta atividade de retomadavaria, mas não depende,de acordo com aacessibilidade do referente aos interlocutores, relativa ao conhecimento partilhado e projetado na interação.Na elaboração deste exemplo, projeta-se aqui um interlocutor capaz de reconhecerde imediato a relação de sinonímia entre os termos e quais aspectos do referente são salientados, em 
função de elementos contextuais relevantes como: i)a informação de que Saussure é natural de Genebra ${ }^{7}$, pressuposta à comunidade de linguistas,ii) o meio de divulgação deste texto, um periódico dedicado a estudos linguísticos. Detectar estes fatores, fundamentais à escolha lexical e à orientação argumentativa do enunciado, é revelar, pois, as marcas do conhecimento partilhado (CAVALCANTE; SANTOS, 2012) projetadas em uma interaçãoao longo da construção dos sentidos.

Se este mesmo enunciado fosse inserido em um contextodesprovido destas âncoras, em especial das informações a respeito do referente (por parte do receptor), o trabalho interpretativo de reconhecimento da sinonímia seria dificultado e diferenciado, mas não inviabilizado.Isto ocorre porque o movimento textual de correferênciapermite ao interlocutor inferir a relação anafórica entre "Saussure" e "mestre genebrino", podendo, inclusive, gerar uma informação contextual nova entre referente e esta referência. Neste percurso, a inferenciação"provê um contexto integrador para informações" (MARCUSCHI, 2008, p. 249), no qual o elemento introduzido é reavaliado em função da intenção comunicativa, e do reconhecimento desta (TOMASELLO, 1999) por parte dos interlocutores.Não por acaso, a interpretação específica de anáforas nominais depende em parte de conhecimentos partilhados e em parte de hipóteses coesivas lançadas pelos interlocutores, provocadas pelo reconhecimento do movimento local de aspectualização do referente enquanto uma atividade textual-interativa, mais geral, de reformulação.

${ }^{7}$ Ou de que as palestras recolhidas para o Cours de LinguistiqueGénéraleforam ministradas na Universidade de Genebra. 
Lembra-nos Marcuschi (2005) que "na sua essência, a anáfora é um fenômeno de semântica textual de natureza inferencial".

Estas hipóteses coesivas, fundamentais ao preenchimento de informações lacunares e textualmente implicitadas, apontam para a relação mais geral de organização e estruturaçãodas categorias linguístico-conceptuais a que são atribuídas um referente e seus elementos fóricos.No exemplo acima, a escolha de outras expressões para retomada referencial, convencionalizadas - como "o filósofo", "o pai do estruturalismo", etc. - implicaria diferentes aspectualizações do referente (eindicaria diferentes intenções comunicativas), fornecendo distintasconfigurações linguístico-conceptuais, isto é, distintas categorizações do referente.

Do ponto de vista situado na produção textual-interativa, há categorização quando um referente é ativado e focalizado em meio a um feixe de significações $(\mathrm{KOCH}, 2004)$,"transformando-se" em um objeto de discurso (MONDADA; DUBOIS, 1995). Na formação de uma cena referencial (TOMASELLO, 1999), seu efeito mais visível é a orientaçãoda atenção (APOTHÉLOZ, 200o) dos interlocutorespara determinados aspectos prototípicos da categoria atribuída ao referente. Em relação a este último movimento, cumpre apontar,a variação dos diversos escopos contextuais ${ }^{8}$ cria distintas saliências, processo fundamental ao mapeamento, localização e circunscrição do protótipo de uma categoria. Esta, por sua vez, organiza "lexical e gramaticalmente

8 Trabalhos como o de Roth \&Shoben (1982), por exemplo, já indicavam a relevância dessa variação, contrastando resultados de efeitos prototípicos obtidos com lexemas isolados e em contexto, para a estruturação das categorias. Para uma visão panorâmica da recepção da teoria dos protótipos na Linguística, ver Martins (2013). 
os domínios conceptuais em termos de perspectiva que se possa adotar sobre eles" (SALOMÃO, 2009, p. 24).

Dado este quadro, podemos afirmar que aperspectivização (TOMASELLO, 1999) do referente, própria mas não específica às anáforas nominais, é responsável por construções de sentido tão distintas na designação de um objeto ou evento do mundo, fornecendonoscaminhos novos para compreendermos como o planeta Vênus, por exemplo, pode ser ora referido como "Estrela da manhã" ora como "Estrela da tarde".

Dentre as manifestações textuais dessa propriedade cognitiva e interacional, estão as sinonímias e os parafraseamentos. Associado a efeitos didáticos $(\mathrm{KOCH}, 2004)$, o parafraseamento é uma atividade de reformulação textual em que dois enunciados são produzidos e encadeados de modo a serem "compreendidos como idênticos" (HILGERT, 2006, p. 276). As paráfrases, portanto, dependem da criação de relações semânticas locais, do tipo associativo, e construídas pelo jogo interpretativo no qual há a predicação de identidade (GÜLICH; KOTSCHI, 1987 apud HILGERT, 2006).

Já as sinonímias destas se diferem em relação ao efeito de simetria proporcionado por uma ou por outra. Enquanto a relação de sinonímia configura simetria entre os sentidos contrastados, as paráfrases geralmente apresentam variação de escopo. Podem ter efeito expansivo, em meio a definições e especificações, ou podem apresentar uma redução, quando resumem ou denominam o objeto de discurso criado anteriormente. Ainda assim, não alteram as relações referenciais do objeto de discurso focalizado e seus elementos referidores, garantindo a 
correferência. Por essa razão, os paralelismos sintáticos - relativos à alteração do núcleo referencial com manutenção da estrutura sintática - são considerados paráfrases simétricas, ou sinonímias, inerentes ao processo de seleção lexical.

\section{Problematizando a correferência à luz da metáfora}

Neste texto trazemos alguns exemplos em que a correferência nominal operada por sentidos pouco convencionalizados, ou estabilizados, responsáveis, ao mesmo tempo, pela manutenção da continuidade referencial, ou a correferência. São casos em que o emprego destas estratégias de referenciação coincide com o emprego de técnicas argumentativas (PERELMAN; OLBRECHTS-TYTECHA, 1996 [1958]) de composição retórica do discurso, como é o caso do emprego de metáforas9. Quando isto ocorre, como veremos abaixo, pelo menos um dos elementos da relação referencial (o objeto de discurso e/ou elemento fórico) deve ser interpretado metaforicamente para que o sentido do enunciado siga a orientação argumentativa ensejada (KOCH, 2005, MARTINS, 2012). Isso significa, entre outras coisas, que a interpretação referencial está condicionada à projeção analógica de campos conceituais bastante distantes e distintos entre si, ou seja, a relação entre estes campos é altamente instável, mas definida dentro de um insight cognitivo (KITTAY, 1987). O processo inferencial específico de reorganização destes campos provoca, assim, uma recategorização

\footnotetext{
${ }^{9}$ A partir das considerações propostas no campo da Linguística Cognitiva, em especial,, mas não só, por Lakoff (1987), Lakoff e Johnson (2002 [1980]), Kövesces (2009). No que tange ao discurso analisado por essa perspectiva, dialoga-se com Semino (2008), Vereza (2007) entre outros.
} 
metafórica (MARTINS, 2012) do referente, não restrita, evidentemente, às estratégias fóricas nominais.

Como visto, o processo geral que caracterizaa anáfora nominalconcerne à alteração da perspectivaadotada sobre um referente, colocando em saliência determinados aspectosatravés de processos de categorização e aspectualização, de forma a mantê-lo em foco na memória discursiva sem, todavia, implicar uma reorganização do domínio conceptual emergente na interação, ou o "universo referencial emergente" (MARCUSCHI, 2005, s/p).Enquanto estratégia interacional, tais escolhas também revelam uma avaliação sobre o referente por parte do interlocutore imprimem uma orientação argumentativa ao texto.

Embora esta definição contemple a noção de que há uma projeção entre domínios para a significação anafórica, deve-se notar, entretanto, que a presença de metáforas, dadas as peculiaridades cognitivas desta, provoca um tipo específico de reorganização destes domínios conceptuais emergentes, ao instaurar uma relação analógica entre um domínio fonte e um domínio alvo. Ou seja, mesmo sendo de natureza textual como qualquer outro tipo de anáfora, entendemos que o cálculo inferencial nestes casos é bastante específico. O próprio Marcuschi (2005, s/p) pode nos ajudar a defender esta ideia, quando aponta que "mesmo no caso da $\mathrm{AD}$ não se requer identidade de significação nem identidade restrita entre anáfora e antecedente".

Assim, especificamos, com algumas diferenças, a proposta de Marcuschipara quem o emprego da metáfora seria um caso de anáfora direta.A escolha por analisar essa manifestação diante de processos 
correferenciais apresenta a vantagem de entendermos como se dão os processos de estabilização referencial de conceitos altamente abstratos e polissêmicos. E este efeito parece mais visível quando observamos dados extraídos de ambientes marcados pela necessidade retórica de estabilização referencial de conceitos altamente abstratos, como é o caso do discurso religioso.

No contexto focalizado, veremos que o grande "potencial pedagógico e persuasivo" atribuído à metáfora(AMOSSY, 200o,p. 158) é amplamente explorado, sendo responsável por um grande número de construções referenciais em que a aspectualização do referente requer uma reorganização entre os domínios conceptuais emergentes na interação, configurando um campo específico para a produção e interpretação textual. O caráter mais propriamente pedagógico das recategorizações metafóricas diz respeito à estabilização inferencial na relação entre estes domínios.

Com base em dados produzidos em contextos retóricos de pregações religiosas, procura-se doravanteilustrar melhor tais afirmações, de forma a discutiras dimensões teóricas e metodológicas dos critérios de classificação de estratégias textuais de retomada referencial em meio à presença de recategorizações metafóricas. Em segundo momento, procuraremos concentrar nossaatenção sobre os efeitos argumentativos da recorrência destas estratégias textualinterativas, afeitas à estabilização discursivo-cognitivados domínios referenciais relevantes à constituiçãodo campo simbólico ${ }^{10}$ (HANKS,

${ }^{10}$ Concernente às escolhas lexicais e aos conceitos aos quais elas remetem. 
2008 [1999]) de práticas ao qual estão associados, isto é, retórica religiosa neopentecostal e seus modos de ação.

\section{Paráfrases e sinonímias metafóricas na retórica neopentecostal}

Diante do exposto, os processos focalizados inserem-se em uma configuração interacional protagonizada por um discurso argumentativo no qual procura-se aproximar uma ética neoliberal de consumo, representada pela ostentação e fruição de bens materiais, a práticas pentecostais de fé e à noção teológica de prosperidade espiritual (RODRIGUES, 2003). A retórica neopentecostal, erigida sobre a exploração simbólica de problemas cotidianos atribuídos a seu público-alvo (MARTINS, 2012), como a miséria e a privação destes bens, fundamenta suaproposta teológica através do oferecimento de soluções religiosas para problemas mundanos. De maneira mais específica, defendemos que o neopentecostalismo caracteriza-se por uma "leitura neoliberal da bíblia” na qual as narrativas bíblicas são enquadradas dentro de frames epistêmicos associados ao neoliberalismon ${ }^{\text {, }}$ como crescimento máximo, competitividade e produtividade (MARTINS, 2015).

A partir desta leitura, assim, são extraídas possíveis soluções para os problemas enfrentados por este público-alvo. Fala-se, assim, de um tipo de exploração simbólica manejada em meio ao dimensionamento simbólico do Pathosprojetivo, relativo a leitura dos valores que o orador

11 O termo "frames neoliberais", portanto, diz respeito àquilo que estánaturalizado, às referências epistêmicas necessárias à "textualização da realidade" $(\mathrm{KOCH}, 2004)$ entrevista no discurso retórico neopentecostal (MARTINS, 2015). 
possui de seu auditório (MEYER, 2007) ${ }^{12}$ e organizado a partir das crenças (religiosas, econômicas, sociais) atribuídas a este público.

Se, por um lado, as igrejas pentecostais tradicionais trabalham com a crença de que a prosperidade financeira e espiritual não corresponde a um comportamento consumista e sim ao acúmulo de riquezas e bens materiais (CAMPOS, 1997), e de que a fé é capaz de determinar as vontades de Deus, as igrejas neopentecostais destacaramse no quadro religioso brasileiro pela incorporação, à teodiceia de seus fiéis, dos padrões de consumo desenvolvidos no Brasil, em especial no início dos anos 90 com a abertura do mercado brasileiro e com o avanço de macropolíticas econômicas neoliberais. Boaventura de Sousa Santos (2013, p. 69), por exemplo, nos aponta que a Teologia da Prosperidade se fundamenta numa legitimação religiosa do capitalismo e das desigualdades resultantes deste sistema econômico em meio a uma exigência de participação cada vez maior no mercado global por setores "renovaristas" do cristianismo. Segundo o autor, a Teologia da Prosperidade parte do pressuposto de que Deus quer que o ser humano seja próspero, ao considerar que este "é incapaz de o ser por si próprio, sendo Deus o princípio legitimador da riqueza e do enriquecimento” (SANTOS, 2013, p. 68).

Por meio da Teologia da Prosperidade, portanto, estas igrejas foram capazes de absorver valores ditados por este modelo socioeconômico eagregar uma dimensão moral à acumulação de riquezas (MARTINS, 2015). Não por acaso, foi possível mostrar

12 Relevante para os estudos por nós desenvolvidos, esta noção de pathos projetivo revelou-se como uma ferramenta interessante para a observação da influência, por exemplo, da teledifusão dos cultos destas igrejas sobre a organização textual-interativa nestes ambientes (MARTINS, 2010). 
(MARTINS, 2011, 2012), por exemplo, que a noção de fé desenvolvida neste contexto é ontologicamente associada à ideia de investimento financeiro, no qual o dízimo é sua expressão máxima. A noção de prosperidade, por sua vez, é ontologicamente associada à noção de consumo: só prospera aquele que consome e está atualizado. Neste percurso, detectamos duas metáforas conceptuais básicas à retórica neopentecostal:"PROSPERIDADE é CONSUMO" e "FÉ É EMPREENDIMENTO", responsáveis por atribuir traços de uma racionalidade secular e empresarial no tratamento dispensado à Teologia da Prosperidade. O método de detecção destas metáforasdesenvolveu-se em meio à análise de enunciados compostos por processos de referenciação, pelos quais chegamos a nichos metafóricos:

um grupo de expressões metafóricas, inter-relacionadas, que podem ser vistas como desdobramentos cognitivos e discursivos de uma proposição metafórica superordenada normalmente presente (ou inferida) no próprio cotexto (VEREZA, 2007, p. 496).

De um ponto de vista quantitativo, os processos de retomada no contexto analisado apresentam alta frequência. Seguindo a classificação, proposta por Koch e Marcuschi (2002), nomeando estes processos com o rótulo "Anáforas Nominais", detectamos um total de 363, ou registros, ou aproximadamente $45^{0} \%^{13}$ (MARTINS, 2011) das ocorrências em nossocorpus, relativo a transcrições de cultos (preenchido com orações e sermões) de duas igrejas neopentecostais

\footnotetext{
${ }^{13}$ Não à toa, o discurso neopentecostal é comumente qualificado como repetitivo e enfadonho (CAMPOS, 1997).
} 
brasileiras, a Igreja Universal do Reino de Deus (IURD) e a Igreja Internacional da Graça de Deus (IIGD). Destas, aproximadamente 30\% são construídas por metáforas.

Já de um ponto de vista qualitativo, a análise dos dados revelanos, por exemplo, que estes processos possuem funções primordiais aos efeitos retóricos almejados pelos oradores. Vejamos os segmentos ${ }^{14}$ 1, 2 e 3, extraídos de um mesmo culto da Igreja Universal do Reino de Deus.

1. Jesus disse... "eu vim para que tenham vida... e vida com abundância (I)" então é a vontade de Deus que você... que todos nós tenhamos uma vida de qualidade... uma vida com saúde... uma boa família... você comer abundantemente... amém? ((platéia: amém)) comer com fartura... amém ((platéia: amém)). Ter fartura na sua casa(II) - "ah... tô com vontade de comer isso... num tem problema... tem aqui... ah quero comer aquilo... num tem problema(III)"- num é isso que você gostaria?" (IURD - Culto 1, p. 152, L. 1-2 15 .

No primeiro enunciado, prosperidade é uma categoria ativada, de maneira implícita, em anteposição às categorias de "miséria", como "abundância" (I) e "fartura" (II), sendo este enunciado recategorizado em meio a uma paráfrase realizada pelo emprego de um discurso direto, com efeito de especificação do escopo de sentido: a fartura é a possibilidade de escolha virtualmente infinita, como podemos notar em

\footnotetext{
14 O sistema de detecção dos dados, cumpre salientar, segue o sistema de notação abaixo: i) Negrito: Referente ativado e categorizado,ii) Itálico: elementos fóricos. iii) Sublinhado: Enunciados metafóricos. Os dados aqui quantificados correspondem a apenas uma parcela do corpus atual de nossas pesquisas.

${ }^{15}$ A transcrição completa dos cultos pode ser encontrada em Martins (2011). As indicações após o exemplo referem-se, respectivamente, a: i) Igreja (Universal ou Internacional); ii) Número do culto; iii) página. iv) Linhas.
} 
(III). Movimento similar de emergênciaocorre na significação incorporada ao termo"vontade de Deus", no qual suas paráfrases recategorizam a noção de abundância, outro elemento fundamental ao domínio referencial próprio à atuação destes oradores.

Em seguida, a noção de prosperidade atrela-se de maneira causal ao objeto de discurso "fé", de relevância central à argumentação deste culto, pois a ele é atribuída uma gama de significados que levam a entender que uma pessoa pode passar de um estado de miséria econômica para um estado de riqueza pelo viés de sua prática incondicional. A fé torna-se o meio para a obtenção dos resultados pessoais almejados. No culto, essa abordagem é feita pela recategorização do item lexical "fé" em meio a atributos indispensáveis à sobrevivência em um mundo neoliberal. Assim ocorre com os exemplos (2) e (3), respectivamente, uma metáfora de personificação e uma ontológica:

2. esse tipo de féque nós cremos segundo a palavra de Deus... é a fé inteligente...(I) é a fé que produz efeito (II)... que faz a gente ter a visão do que Deus quer da nossa vida...(III) (IURD - CULTO 1: P. 151 L. 27-28).

3. A sua fé é a ponte entre você e Deus...(I) quando você usa essa fé... (II) quando você atravessa essa fé... (III) ou essa ponte... (IV)você tem Deus à disposição... Ele está ali pronto pra atuar em sua vida... (IURD - CULTO ı, P. 151 L. 10-12)

A metáfora de personificação veiculada em (2) atribui à "fé" uma propriedade humana pelo emprego adjetivo de "inteligente"; uma restrição fundamental para a interpretação desta metáfora está na 
incorporação de um aspecto da inteligência que é valorizado no quadro neoliberal: a racionalidade prática. A progressão referencial do item atesta essa observação: quando retomado no segmento (II), uma paráfrase do segmento (I), ele perde a metaforicidade e direciona a interpretação da metáfora para um campo mais estável de significação, no qual a fé tem efetividade imediata (produz efeito). Já em (III) ocorre um movimento muito interessante: a retomada (elíptica) de "fé" é novamente por meio de um enunciado metafórico que, desta vez, atribui legitimidade religiosa à racionalidade prática e à fé efetiva. Quando relacionado ao primeiro excerto, é possível obter a informação de que "o que Deus quer da nossa vida" refere-se à fartura e à abundância, aspectos centrais à prosperidade. Vale notar que nos segmentos II e III podemos perceber também uma função discursiva de estabilização do domínio metafórico: a fé, deve embutir, entre suas categorias conceptuais, alguma noção pragmática de valor de uso.

Já o enunciado (3) fornece uma gama de indícios que refletem a maneira como a fé deve ser encarada para que possa ser efetiva no mundo: é uma metáfora ontológica que permite que se entenda este atributo humano enquanto algo concreto, algo que faz parte da experiência da maior parte do auditório ali presente. No caso, o emprego do verbo "atravessar" está ancorado ao framede conhecimento evocado pelo item lexical de "ponte", evocando dentre os conhecimentos que lhe são atribuídos a propriedade de facilitar o acesso entre lugares separados (o fiel e Deus) por algum tipo de obstáculo associável às incursões malignas de entidades demoníacas., como um Veículo ou Meio. 
O segmento (II), pelo índice verbal, procura estabilizar a categoria fé de forma que esta seja vinculada a alguma ideia racional e pragmática de uso, fato muito recorrente nos cultos. Este é um dado de caráter claramente estabilizador, circunscrevendo os campos referenciais criados em pela metáfora definicional evocada no segmento (I). Nos segmentos (III)e (IV), há novarecategorização metafórica de "fé" por via de paralelismos sintáticos, e as delimitações impostas pela remissão anterior circunscrevem estas metáforas ao campo do uso. Assim, da relação metafórica proposta no enunciado (I), eno qual "fé" é primeiramente situada no domínio alvo, foi possível derivar as metáforas observadas em (III)e(IV).

Oobjeto de discurso "fé inteligente", estabilizado no extrato 2, situa-se no domínio fonte das relações metafóricas estabelecidas através das remissões a ele feitas, indicando uma relação metafórica, isto é, de projeção e cruzamento de domínios da experiência, entre os próprios enunciados ligados por mecanismos fóricos. Os alvos, vale notar, pertencem ao domínio semântico-referencial forjado em (I).

Os efeitos destas operações, em termos argumentativos, reverberam na classificação de práticas fundamentais a estas igrejas, como as doações em forma de dízimos e ofertas. Vejamos o exemplo abaixo, extraído já na conclusão do sermão:

4. Você tem que lutar... você tem que agir a sua fé...(I) você tem que tomar atitude... que eu não posso tomar... essa atitude é sua... pra que você venha a conquistar (II)... amém pessoal? ((platéia: amém)). Eu quero convidar as pessoas que querem fazer umpacto com Deus... (III) com o Senhor Jesus... você quer fazer dele a pessoa mais importante na sua vida... você quer fazer um 
pacto com Ele... Ele tem que ser o primeiro na sua vida. Pra haver essa sintonia... essa comunhão... (IV) pra haver essa cooperação....(V) sua com Ele... Ele com você. Você tem que fazer um pacto com Ele... é um casamento com Deus... você vai entregar a sua vida pra ele (VI). (IURD - CULTO 1, P. 154 L. 1-9)

Após a afirmação de que o Diabo é o responsável pelo sofrimento dos fiéis ${ }^{16}$, o orador procura orienta-los sobre o melhor método de superação destas adversidades, no qual, por exemplo, a informação de que a fé é uma ponte, estabilizada em momentos anteriores do culto e recategorizada em termos das intenções comunicativas mais gerais destes oradores. O objeto de discursofé,recategorizado em termos de Veículo, ou Meio (FÉ É PONTE), é re-ativado, como podemos ver no segmento (II). Em (I), porém, vê-se que esta informação nova sobre o referente érecategorizada em termos de luta, combate. Assim, delimitase um percurso inferencialno qual a garantia de uma travessia bemsucedida, a prosperidade terrena,está condicionada a um acordo entre Deus e o fiel (III), parafraseado e recategorizado em termos de uma harmonia entre as partes (IV), reforçada pelo emprego do paralelismo entre os itens sintonia e comunhão. Já em (V), o paralelismo sintático,correferência para (IV), introduz um frame no qualo orador estabiliza o tipo de acordo em termos de uma colaboração mútua.

Em (VI), por fim, pode-se visualizar o processo de definição das partes nesta colaboração: ao fiel cabe o "sacrifício", metáfora muito comum nestes ambientes (MARTINS, 2011) para descrever o percurso

\footnotetext{
${ }^{16}$ Considera-se, neste contexto, que a humanidade vive uma constante Guerra Santa entre Deus e o Diabo. A este respeito, ver Martins (2011) ou, numa chave sociológica, Swatowiski (2007).
} 
de glória realizado pelos grandes personagens bíblicos, como Jesus, Jó, entre outros, enquanto uma experiência similar ao dízimo e às ofertas.

No ambiente retórico descrito, a importância destes movimentos de recategorização e estabilização é fundamental para que os efeitos argumentativos sejam atingidos com algum grau de sucesso. Como vimos, porém, a descrição deste percurso requer uma análise pormenorizada de aspectos do contexto, em termos de intencionalidade e de reconhecimento da função comunicativa (SANDIG, 2009), fundamentais à organização da categoria fé tal qual deve ser compreendida e praticada nestes ambientes.

\section{Considerações finais}

No âmbito da Linguística Textual, deve-se entender que o processo inferencial atinente às recategorizações metafóricas é de natureza específica. No caso em que ocorrem por meio de atividades textuais de reformulação por retomada, como nas sinonímias e paráfrases, pode-se vislumbrar com mais clareza a especificidade desse processo, relativa à exigência de uma projeção analógica entre domínios conceptuais, algo que não ocorre em anáforas nominais nãometafóricas. Apesar da continuidade referencial garantida pela retomada, há a necessidade de reorganização dos domínios conceptuais em um arranjo específico para a significação.

O "insight cognitivo" próprio às metáforas, o tipo especifico de operação mental exigida para a interpretação delas, como apontado à epígrafe deste texto e empiricamente sustentado pela Linguística 
Cognitiva, nos permite sugerir um estatuto singular nos estudos do texto às atividades de retomada por metáfora, ao constituíremformas específicas para construção de sentidos em um texto(MARTINS, 2012). Em muito colaboram Mondada eDubois (2003 [1995]) com essa proposição, quando afirmam que:

De um ponto de vista linguístico, quando um contexto é reenquadrado (GOFFMAN, 1974), as categorias podem ser reavaliadas e transformadas, juntando diferentes domínios, como na metáfora, na metonímia e na metalepse (MONDADA; DUBOIS, 2003 [1995], p. 25).

Embora tenhamos analisado um pequeno conjunto de movimentos conceituais, pudemos perceber como estas atividades contribuem para o estabelecimento de traços que não eram antes compartilhados entre os domínios conceptuais da relação anafórica, implicando em atribuição de traços e elementos novos aos próprios domínios e redes conceituais. Como visto, o objeto de discurso "fé", recategorizado metaforicamente em termos de "ponte" no culto analisado, adquire feições bastante peculiares quando constantemente conceptualizado à luz de uma racionalidade prática na quala busca de conforto espiritual através do consumo marca a teodiceia dos cristãos neopentecostais.

A identificação destes traços, construídos ao longo dos sermões e orações neopentecostais, é resultado da composição metafórica que procura estabilizar essa analogia entre os domínios referenciais. Estes, por sua vez, podem ancorar a introdução e exploração de metáforas específicas, inserindo-as em domínios conceituais fundamentais ao ato 
suasório em direção às verdades que sustentam a retórica neopentecostal, validando-as localmente.

De um ponto de vista panorâmico, a alta recorrência destes mecanismos indica-nos a presença de uma estratégia de circunscrição conceptualde referentes fundamentais à retórica praticada pelos líderes das igrejas neopentecostais, como miséria, pobreza, prosperidade e fé. Esta alta recorrência também nos indica o emprego de estratégias que procuram manter um objeto de discurso na memória discursiva $(\mathrm{KOCH}$, 2002) sem recorrer à repetição lexical, e pelas quais se percebe a fixação e estabilização de determinados percursos epistêmicos para a interpretaçãoda realidade do ponto de vista neopentecostal. No caso, vimos a importância destas estratégias para a fundamentação de que a fé, quando assimilada de maneira correta, é caminho certo para a prosperidade, notadamente categorizada em meio a noções como fartura e abundância.

Por fim, entendemos que a repetição destes movimentos referenciaisnos permitem ver como os sentidos metafóricos dos enunciados ligados à retórica neopentecostal adquirem estabilidade cognitivo-discursiva, e como as categorias linguísticas vão sendo reorganizadas e reconfiguradas, instituindo pontos cognitivos de referência ( $\mathrm{ROSCH}, 1978)$ particulares, característicos de domínios conceptuais próprios a este movimento religioso e social. São fundamentais, assim, à constituição de uma espécie denorma neopentecostal, na qual a interpretação de diversos termos-chave é constantemente sedimentada em um campo simbólico potencialmente partilhado entre os membros destas comunidades. 


\section{Referências}

AMOSSY, Ruth. L'argumentationdans le discours. Nathan, Paris, 2000. APOTHÉLOZ, D. Référersans expression référentielle: gestion de la référence et opérations de reformulation dans des sequences métalinguistiques produites dan sun etache de redaction conversationelle. Pragmatics in 2ooo: selected papers from the $7^{\text {th }}$ International Pragmatics Conference, Antwerp. 2 (1). p. 30-38, 2000.

BENTES, A. C.; ALVES FILHO, F. Apresentação. Linguagem em discurso. v. 12, n. 3, p. 649-655, 2012.

CAMPOS, L. S. Teatro, templo e mercado: organização e marketing de um empreendimento neopentecostal. Vozes. São Paulo, 1997.

CAVALCANTE, M. M.; SANTOS, L. W. Referenciação e marcas do conhecimento partilhado. Linguagem em discurso. v. 12, n. 3, p. 657-682, 2012.

FILLMORE, C. Frame semantics. Linguistics in the Morning Calm.Soeul; Hanshin. The Linguistic Society of Korea. p. 111-137, 1982.

GOFFMAN, E. Frame analysis. New York: Harper \& Row, 1974.

HANKS, W. O que é contexto. In: BENTES, A. C.; REZENDE, R. C.; MACHADO, M. A. (Eds.). Língua como prática social: das relações entre língua, sociedade e cultura a partir de Bourdieu e Bakhtin. São Paulo: Cortez Editora. p. 169 - 203, 2008; [1999].

HILGERT, J. G. Parafraseamento. In: JUBRAN, C. C. A.; KOCH, I. V. (Orgs).

Gramática do Português Culto Falado no Brasil: Vol. 1: a construção do texto falado. Campinas, SP: Ed. da UNICAMP, 2006. p. 275-300 JUBRAN, C. C. A. Introdução - A perspectiva textual-interativa. In: JUBRAN, C. C. A.; KOCH, I. V. (Orgs). Gramática do Português Culto Falado no Brasil: Vol. 1: a construção do texto falado. Campinas, SP: Ed. da UNICAMP, 2006, p. 27-38. KITTAY, E. Metaphor: its cognitive force and linguistic structure. OUP: Oxford, 1987. 
KOCH, I. V. Desvendando os segredos do texto. São Paulo Cortez, 2002. Introdução à Linguística Textual: trajetória e grandes temas. São Paulo:

Martins Fontes, 2004.

. Referenciação e orientação argumentativa. In: KOCH, I. G. V., MORATO, E. M.; BENTES, A. C. (Orgs.). Referenciação e discurso. São Paulo: Ed. Contexto, 2005 .

. Progressão referencial, progressão temática e progressão tópica. In KOCH, I. V. As tramas do texto. Rio de Janeiro: Nova Fronteira, 2008. p. 119-134. KOCH, I. V.; CUNHA-LIMA, M. L. Do cognitivismo ao sócio-cognitivismo. Introdução à linguística: fundamentos epistemológicos, Vol. 3. São Paulo: Cortez, 2004 .

KÖVECSES, Z. The effect of context on the use of metaphor in discourse. Iberica. v. 17, n. 1. p. 11-24, 2009.

LAKOFF, G. Women, fire and dangerous things: what categories reveal about the mind. Chicago: The University of Chicago Press, 1987.

LAKOFF, G.; JOHNSON, M. Metáforas da vida cotidiana. Campinas: Mercado das Letras; São Paulo: Educ, 2002; [1980].

LEEZENBERG, M. Da Linguística Cognitiva às Ciências Sociais. Tradução de Erik Fernando Miletta Martins. Revista Investigações, v. 28, n. 2, 2015; [2013].

MARCUSCHI, L. A.; KOCH, I. V. Estratégias de referenciação e progressão textual na língua falada. In: ABAURRE, M. B.; RODRIGUES, A. Gramática do português falado, vol. VIII. Campinas: Ed. da UNICAMP, pp. 31-58, 2002.

MARCUSCHI, L. A.O barco textual e suas âncoras. In KOCH, I. V.; MORATO, E. M.; BENTES, A. C. (Orgs). Referenciação e Discurso. São Paulo: Contexto, 2005. p. 53-102.

MARCUSCHI, L. A. Referenciação e progressão tópica: aspectos cognitivos e textuais. Caderno de estudos linguísticos, Campinas, v. 48, n. 1, p.7-22, 2006. MARCUSCHI, L. A. Produção textual, análise de gêneros e compreensão. São Paulo: Parábola Editorial,2008.

MARTINS, E. F. M. O papel da teledifusão na organização textual-interativa da retórica neopentecostal. Communication, Cognitionand Media (Comunicação, 
Cognição e Media). Braga: Aletheia - Associação Científica e Cultural da Faculdade de Filosofia da UCP. v. 2. p. 191-202, 2010.

MARTINS, E. F. M. O percurso sociocognitivo das recategorizações metafóricas: construção de sentidos na retórica neopentecostal. Dissertação de Mestrado. Universidade Estadual de Campinas (UNICAMP), 2011.

MARTINS, E. F. M.; MORATO, Edwiges Maria. Referenciação e orientação argumentativa na retórica neopentecostal: o percurso sociocognitivo das recategorizações metafóricas. In CAVALCANTE, M. M.; LIMA, S. C. (Orgs.). Referenciação: teoria e prática. São Paulo: Cortez, 201. p. 86-104. MARTINS, E. F. M. Semântica dos protótipos. In FERRAREZI JÚNIOR,C.; BASSO, R. (Orgs.). Semântica, semânticas: uma introdução. São Paulo, Contexto, 2012. MARTINS, E. F. M. Frames neoliberais na retórica neopentecostal: aspectos referenciais e sociocognitivos. Tese de doutorado. Universidade Estadual de Campinas (UNICAMP), 2015.

MARTINS, H. Sobre linguagem e pensamento no paradigma experiencialista. Veredas. v. 6, n. 1, p. 75-90, 2002.

MEYER, M. A retórica. Trad. Lineide L. S. Mosca. São Paulo: Ática, 2007. MINSKY, M. A Framework for Representing Knowledge. In: The Psychology of Computer Vision. New York: McGraw-Hill, 1975.

MONDADA, L.; DUBOIS, D. Construção dos objetos de discurso e categorização: uma abordagem dos processos de referenciação. In: CAVALCANTE, M. et al. (Orgs.). Coleção clássicos da linguística: Referenciação. São Paulo: Contexto, p. 17-52, 2003; [1995].

MORATO, E. M.; KOCH, I. V. Linguagem e cognição: os (des)encontros entre a linguística e as ciências cognitivas. Cadernos de Estudos Linguísticos, Campinas, n. 44, p. $85-91,2003$.

MORATO, E. M. et al. Processos implícitos, contextuais e multimodais na construção referencial em conversações entre afásicos e não afásicos: relato de pesquisa. Linguagem em Dis(curso), v. 12, n. 3, p.711-742, 2012. 
MORATO, E. M. et al. O papel dos frames na organização do tópico discursivo e na coesividade comunicacional na interação entre afásicos e não afásicos. Cadernos de Estudos Linguísticos, Campinas, v. 59, n. 1, p. 91-110, abr. 2017. MORATO, E. M. Linguística Textual e cognição. (no prelo). PERELMAN, C.; OLBRECHTS-TYTECHA, L. Tratado da argumentação: a nova retórica. Tradução de Maria Ermantina Galvão. São Paulo: Martins Fontes, 1996; [1954].

RODRIGUES, K. Teologia da Prosperidade: Sagrado e Mercado. São Paulo: Edições FAFICA, 2003. ROSCH, E. Principles of categorization. In: ROSCH, E.; LLOYD, B. (Eds.). Cognition and Categorization. Hillsdale, New Jersey: Lawrence Erlbaum Associates, 1978.

ROTH, E.; SCHOBEN, E. The effect of context on the structure of categories. Cognitive Psychology, v. 15, p. 346-378, 1983.

SALOMÃO, M. M. Teorias da linguagem: a perspectiva sociocognitiva. In: MIRANDA, N. S.; SALOMÃO, M. M. Construções do Português do Brasil: da gramática ao discurso. Belo Horizonte: Ed. da UFMG,2009. p. 20-32.

SALOMÃO, M. M. Razão, realismo e verdade: o que nos ensina o estudo sóciocognitivo da referência. In: KOCH, I. G. V.; MORATO, E. M.; BENTES, A. C. (Orgs.). Referenciação e Discurso. São Paulo: Contexto, 2005. SALOMÃO, M. M. A questão da construção do sentido e a revisão da agenda dos estudos da linguagem. Veredas. v. 3, n..1, Jan/Jun, 1999.

SANDIG, B. O texto como conceito prototípico. In: WIESER, H. R.; KOCH, I. G. V. (Orgs.). Linguística Textual: perspectivas alemãs. Rio de Janeiro: Nova Fronteira, 2009. p. 47-72.

SANTOS, B. S. Se Deus fosse um ativista dos direitos humanos. São Paulo: Cortez, 2013.

SEMINO, E. Metaphor in discourse. New York: Cambridge University Press, 2008. SWATOWISKI, C. Texto e contextos da fé: o discurso mediado de Edir Macedo. Religião e sociedade. Rio de Janeiro, v. 27, n. 1., p. 114 - 131, 2007. 
TANNEN, D. Whatis in a frame. In: TANNEN, D. Framing in discourse. New York: OUP, 1993. p. 14-56.

TOMASELLO, M. Cultural origins of human cognition. Massachussets: Harvard University Press, 1999.

VEREZA, S. Metáfora e argumentação: uma perspectiva discursiva. Linguagem em (dis)curso. v. 7, n. 3, p. 487-506, 2007.

Recebido em 20/11/2017.

Aprovado em 22/12/2017. 